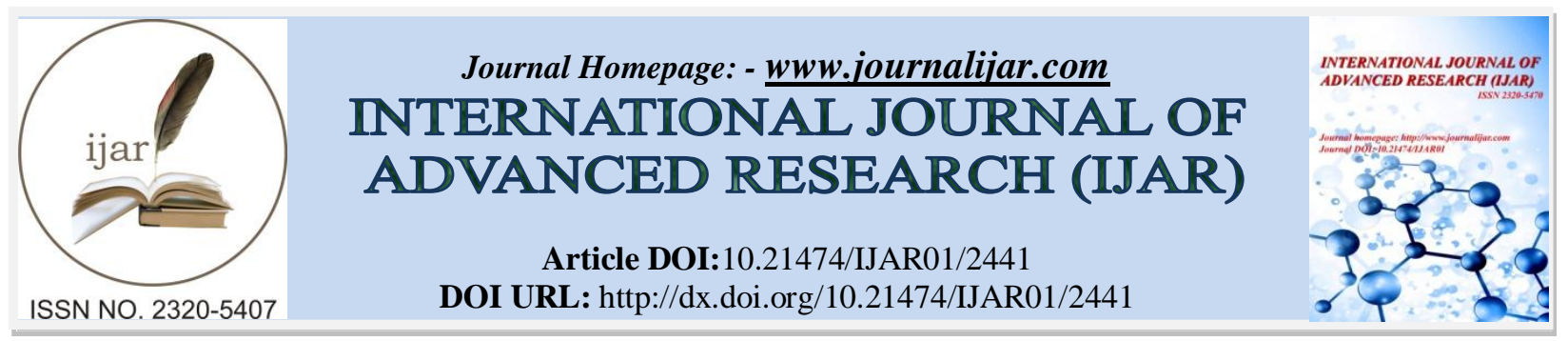

RESEARCH ARTICLE

\title{
SMART PARKING SYSTEM BASED ON RFID AND CLOUD TECHNOLOGIES.
}

Mrs. Shagupta M. Mulla ${ }^{1}$, Ms. Shubhangi S. Magdum², Ms. Komal K.Surve²,Ms. Monika M. Guravªnd Ms. Shilpa S.Magdum².

1. Assistant Professor, Department of CSE,BharatiVidyapeeth's College Of Engineering, Kolhapur.

2. B. E. Students, Department of CSE, BharatiVidyapeeth's College Of Engineering, Kolhapur.

\section{Manuscript Info}

…......................

Manuscript History

Received: 20 October 2016

Final Accepted: 22 November 2016

Published: December 2016

Key words:-

RFID, cloud technology,

parking systems

\section{Abstract}

This paper gives an idea about algorithm that maximizes the efficiency of smart parking system using RFID and the cloud technologies.Here we have used Google map to check the geographical location of user.It allows users automatically find available parking slot at the low cost depend on latitude and longitude of the user.System calculates users parking cost by assuming the total number of available places in each car parking. Here user will search a free parking slot.After receiving a request from user and if the current car parking slot is full then this system suggests a new car parking slot. So system helps users to find optimal parking space in minimum time.

Copy Right, IJAR, 2016, All rights reserved.

\section{Introduction:-}

In the traffic management systems, a parking system was created to minimize the cost of people. Nowadays, the normal method of searching a parking spot is manual where the driver normally searches a slot on the road by luck and experience. This method takes too much time and efforts and causes a worst case that failing to find any park slot. The alternative is to search specific car park with maximum capacity. This is not a normal solution because the car park will be far away from the user destination.

In recent years, research has used vehicle-to-infrastructure interaction with the support of various wireless network technologies such as radio frequency identification (RFID), wireless mesh network, and the Internet [2]. This project provides information about nearest parking area for the user and making reservation using smart phones or tablet. To solve the manual car park problems and take benefit of the technology, the Internet is used for many reasons in smart parking system. This project develops an effective smart parking system using RFID and cloud technologies. So this project builds each car park as a network, and the data include the GPS location. This project also implements system in an open-source platform by using RFID and cloud.

\section{System Architecture:-}

We designed a software as a client application that runs on Smart phone based on the android platform, which was built from the ground up to enable developers to create compelling mobile applications that can take full advantage of all functionalities that a handset can offer.

Corresponding Author:- Mrs. Shagupta M. Mulla.

Address:-Assistant Professor, Department of CSE, BharatiVidyapeeth's College Of Engineering, Kolhapur. 


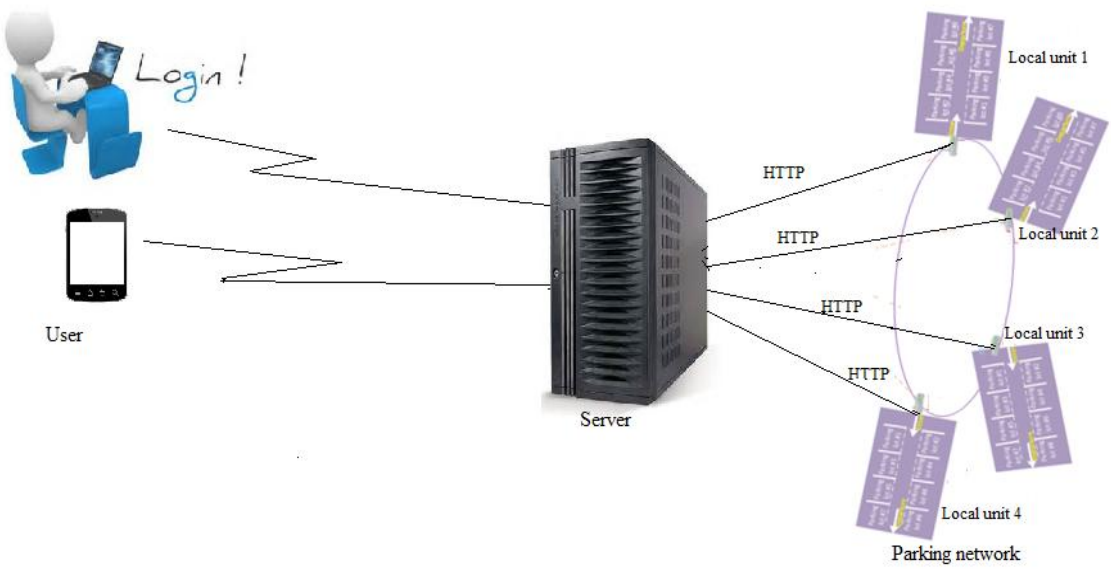

Fig 1:- System Architecture

The smart parking system is derived by using internet and RFID for searching car parks, the RFID reader used for counting available parking slots in each car park. This system provides an idea to controldrawback in the car park and helps to minimize wasted time in looking for a parking space. After login the user can select a nearest or convenient parking slot by using following algorithm. If allocated time is finished then system will not allow car park in particular slot.

\section{Algorithm:-}

Input:- User U, RFID card rf_id,User_Location[lat,log], parking P,parking[lat][log], parking Pcount,location between user and parking UtoP,radius difference rd

Output:-Indatetime, outdatetime, Parking History

1. User Register with system and get uid

2. Set rf_id to register user

3. Add Amount In Wallet card

4. Go to online Transaction

5. Check amount in Wallet

If (Wallet amount $<$ minimum parking amount)

go to step 4

else

go to step 6

6. Get User_Location[lat,log]

7. Search Nearest Parking location within user radius

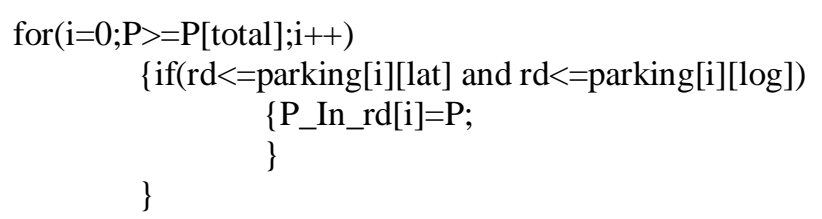

8. sort parking area by distance which is available within Radius

9. Show Point on map

10. Select Parking Area

11. swap RFID card on RFID Sensor At Parking Area

12. Read rf_id value and verify user and increase decrease parking count of parking area

for $(\mathrm{i}=0 ; \mathrm{U}>=\mathrm{U}[$ total $] ; \mathrm{i}++)$

$\{$ if(U[rf_id]=rf_id)

\{true;

if(U[rf_id]==In $)$

\{Pcount--;

outdatetime=datetime; 


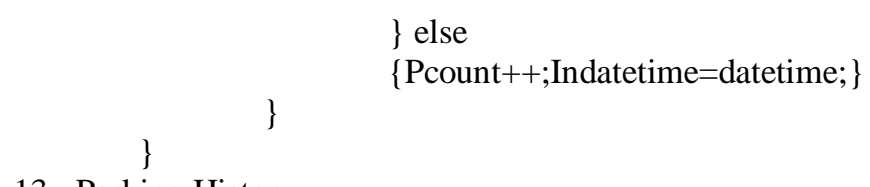

Fig2:-Algorithm of smart parking system.

Above algorithm shows the operation of smart parking system. First, user is registered inthe system and it will get user id. If user interested in online transaction then the user must add amount in wallet card.If wallet amount is not enough for paying parking amount then user can check their amount in wallet, and if wallet amount is sufficient for paying parking amount then get user location. Then user searches nearest parking location within user radius and this location displays or pointing on the map. Finally, user can select suitable parking location and when user entered in that particular parking area then swaps the card using RFID sensor, at that time counter incremented by one. Similarly, user exit (out) by card swap, then counter decremented by one.

\section{Flow Chart:-}

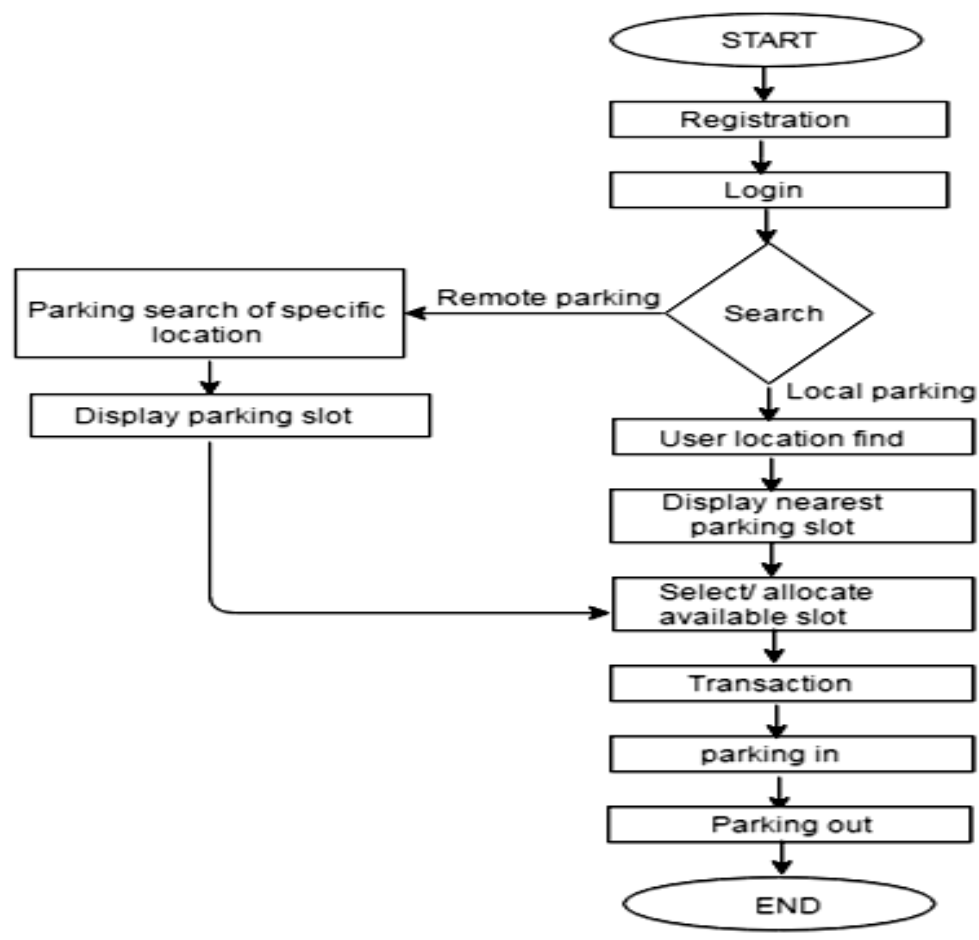

Fig3:-System operation.

If user wants to park a car in suitable parking area, then he must registered and login to our smart parking system. After completion of login, two possibilities are arises, if user wants to park a car in another parking area then user can use pre-parking system else user can find nearest location. Then user can get number of parking area and selects suitable parking area within that parking area. Transaction is done through swap card using RFID sensor when user entered in available slot. User also can make exit from the system by using swap card.

\section{Implementation:-}

In this system admin can provide user id and passwords to students and users with simple secure and easily accessible Android application. This application is becoming an inevitable thing in our fast developing environment and current life style. Application is developed for mobile device supporting Android OS 4.4 above. All database is securely stored on Cloud.

In this system PHP, Java technologies, My SQL Server-2008, Eclipse IDE, ADT bundle and JDK tools are used for implementation. 


\section{Conclusion:-}

Now-a-days, current system takes time, effort and may lead to the worst case of failing to find any park space if the driver is driving in a city with high vehicle density.

In the traffic management systems, a parking system was created manually to find out vacant parking slot. This system used vehicle-to-infrastructure interaction with the help of the radio frequency identification (RFID) and the Internet. It improves efficiency of the system to find out optimal parking space. So it builds each car park as a network, and the data includes the GPS location. It implements system in an open-source platform by using RFID and cloud.

\section{References:-}

1. D.-J. Deng, “A Cloud-Based Smart-Parking System Based on Internet-of-Things Technologies”, IEEE -2015, DOI - 10.1109/ACCESS.2015.2477299.

2. F. Akyildiz, X. Wang, and W. Wang, 'Wireless mesh networks:A survey," Computer Network, vol. 47, no. 4, pp. 445_487, Mar. 2005. 